Note: This article has been accepted for publication at Computational Communication Research.

The State and Evolution of Communication Research:

A Topic Modeling Analysis of 20,000 Journal Article Abstracts from 1918-2015

\author{
Stephen A. Rains \\ University of Arizona \\ srains@email.arizona.edu \\ David M. Keating \\ University of New Mexico \\ John A. Banas \\ University of Oklahoma \\ Adam Richards \\ Furman University \\ $\&$ \\ Nicholas A. Palomares \\ University of California, Davis
}




\begin{abstract}
Tremendous growth in the communication discipline during the past century has raised fundamental questions about what it means to study human communication. This project reports an attempt at answering such questions by exploring the themes that animate communication scholarship over time and across journals sponsored by different scholarly organizations. We used topic modeling to examine the abstracts of more than 20,000 articles across 22 journals from their beginnings through 2015. The results offer insights about the state and evolution of communication scholarship. Research has evolved from being predominately focused on pedagogy to examining a wide variety of phenomena that mark an increasingly diverse field. The role of scholarly organizations in contributing to disciplinary fragmentation is considered, as well as the field's relatively limited focus on underlying and contextually-transcendent processes in favor of specific communication contexts.
\end{abstract}

Keywords: communication, scholarship, journal articles, topic modeling, latent Dirichlet allocation 


\section{The State and Evolution of Communication Research:}

\section{A Topic Modeling Analysis of 20,000 Journal Article Abstracts from 1918-2015}

Although the study of human communication likely extends to ancient Greece, the past century has been particularly consequential in its evolution (for reviews, see Benson, 1985; Bryant \& Pribanic-Smith, 2010; Delia, 1987; Rogers, 1994). The number of communication doctoral degrees increased substantially from the 1920s through 2010 (Knower, 1935, 1936; National Communication Association, 2016; Thomas, 1968), which coincides with increased publication venues. From a handful of journals in the early 1900s, the National Communication Association (NCA), regional associations in the United States (e.g., Western States Communication Association), and the International Communication Association (ICA) currently sponsor over 20 journals dedicated to original communication research. This significant growth raises fundamental questions about the nature of communication research and how scholarship on central phenomena has evolved among different academic communities (Benson, 1985; Berelson, 1959; Bryant \& Pribanic-Smith, 2010; Delia, 1987; Eadie, 2011; Woolbert, 1923). Ensuring a robust future requires understanding our past. To this end, we use topic modeling to empirically explore the evolution of themes animating communication scholarship. Working from the assumption that the study of human communication is reflected in the content of original scholarship published in communication journals, we examine the abstracts from more than 20,000 articles published in journals sponsored by regional, national, and international communication organizations from their beginnings as early as 1918 through 2015 . We identify the most prominent themes that define research published in communication journals and consider differences over time and across journal types (i.e., regional, national, international). We add to the tradition of reflecting on progress in communication research (e.g., Benson, 1985; 
Berelson, 1959; Craig, 2018; Levine, 2013; Rogers \& Chaffee, 1983; Swanson, 1993) by offering a descriptive account and constructive insights about the evolution of constituent foci in communication scholarship.

\section{Evaluating the Status of Communication Research}

The field of communication has a rich history. The National Association of Academic Teachers of Public Speaking (established in 1914) appears to be the oldest formal organization dedicated to communication research. This organization, which changed names several times before becoming NCA in 1997, was formed by dissatisfied English teachers who felt like speech did not have proper attention in English departments (O’Neil, 1915). Regional communication associations like the Western States Communication Association (established in 1929) and the Central States Communication Association (established in 1931) concomitantly emerged to represent local interests in communication pedagogy and research. In 1950, the National Society for the Study of Communication aimed to move beyond speech education and the study of rhetoric by embracing social scientific approaches and encouraging an interdisciplinary membership (Weaver, 1977). In 1969, it evolved into ICA with four divisions dedicated to interpersonal, mass, and organizational communication along with information systems and members from almost 30 countries (Weaver, 1977). As of 2020, ICA had grown to include 23 divisions and NCA sponsored 49 different divisions.

The diverse perspectives driving the formation and evolution of these major scholarly organizations dedicated to the study of human communication has resulted in a vibrant field marked by a tapestry of varying metatheoretical approaches and research foci. Perhaps due in part to this diversity, our discipline has a longstanding tradition of engaging in self-reflection. In one of the earliest inquiries, Berleson (1959) considered progress in communication research 
from the early 1930s until the late 1950s and reported a great deal of pessimism about the field's future. Later reviews have cataloged the growth of the field as a coherent discipline (Benson, 1985; Delia, 1987; Rogers, 1994) and considered changes during more recent years (Bryant \& Pribanic-Smith, 2010). Other notable works have broached topics like our shared identity (Wiemann, Hawkins, \& Pingree, 1988), disciplinary fragmentation (Eadie, 2011; Swanson, 1993), the future (Rogers \& Chaffee, 1983), and numerous other concerns (e.g., Bryant \& Miron, 2004; Chakravartty, Kuo, Grubbs, \& McIlwain, 2018; Levine, 2013; Miller, 1983; Splichal \& Mance, 2018). Researchers have also employed empirical methods to investigate the wellbeing of our discipline, examining issues ranging from journal citation networks (Feeley, 2008; Rice, Borgman, \& Reeves, 1988) to the connections among communication theories (Chung, Barnett, Kim, \& Lackaff, 2013).

One foundational issue of many inquiries about our discipline involves what it means to study human communication. The topics, areas of inquiry, and domains of theoretical understanding that define communication research are often debated and contested (e.g., Eadie, 2011; Swanson, 1993; Wartella, 1996). Although value certainly exists in debating what should constitute communication research, another approach to understand the study of human communication is to examine what is actually being investigated. Indeed, scholars have conducted a manual content analysis of articles published in the Journal of Communication focusing on the nature of authors, methods, theory development, and other issues (Walter, Cody, \& Ball-Rokeach, 2018). Other researchers have used hierarchical cluster analysis to identify themes in titles published in Human Communication Research (Stephen, 1999) and the Journal of Broadcasting \& Electronic Media (Rice, Chapin, Pressman, Park, \& Funkhouser, 1996). 
Although existing narrative reviews and manual content analyses have undoubtedly yielded important insights, both are limited in important ways. Narrative accounts tend to focus more on the origins of the field, a small number of influential scholars, or important research programs as perceived by the authors. In describing his own book, for example, Rogers (1994) notes that other narrative histories focus "on the big names and the big institutions of the history of communication study" (p. xi). Narrative reviews also tend to be limited in scope, focusing exclusively on specific subfields like mass communication (e.g., Lowery \& DeFleur, 1995; Sherry, 2004) or intentionally omitting others like rhetoric (Rogers, 1994). Finally, most of the major histories of our field are dated (e.g., Delia, 1987; Dennis \& Wartella, 1996; Lowery \& DeFleur, 1995; Rogers, 1994; Schramm, 1997). One exception is Sherry’s (2004) history of media effects research, which was published more than a decade ago. Manual content analyses are similarly limited in scope, particularly with regard to the journals, topics, and time frames selected. For example, one analysis might focus exclusively on a single journal's evolution (e.g., Rice et al., 1996), while another might be concerned only with recent publication trends in one area of the field (e.g., Keating \& Totzkay, 2019).

Perhaps due in part to some of the limitations of narrative reviews and manual content analyses, communication scholars have begun to capitalize on contemporary computational methods involving text analysis to describe bodies of research that overlap with communication (Peng et al., 2012). In particular, Günther and Domahidi (2017) used topic modeling to examine more than 10,000 abstracts from 19 journals and evaluate trends in interdisciplinary communication scholarship. Most of the journals in their sample focused on media and journalism or were broadly interdisciplinary and sponsored by societies representing fields like social psychology, journalism, advertising, or linguistics. The fifteen most prevalent topics 
appearing in these journals included (in rank order): education, marketing and PR, media use, comparative research and media stereotypes, health, new media, survey and interview research, media violence and media effects, religion, and family and development. Efforts such as this one add to our understanding of interdisciplinary communication scholarship and also highlight the need to focus on publication outlets more central to our field.

Communication contains a panoply of perspectives spanning the behavioral sciences and humanities. Given this discontinuity, organizations like NCA and ICA and their regional brethren have been prominent in our field's evolution. They have offered structure for our growth much like a scaffold facilitates the construction of an edifice. The journals that these organizations sponsor formalize and legitimatize phenomena central to our field. Considering the works published in these outlets thus offers one valuable approach for tracing our collective history and evolution. Accordingly, we use topic modeling to examine the most prevalent themes appearing in ICA, NCA, and regional journals from their beginnings until 2015. Like Günther and Domahidi (2017), we focus on journal article abstracts to reduce noise and isolate central elements. We examine the prominent topics studied in our journals, their evolution over time, and changes in topic pairs. Addressing these issues will offer insights about the state and evolution of communication scholarship via data-driven observations about what communication researchers have collectively studied. We formally state our objectives in the following research questions (RQ):

RQ1: What are the most prominent topics appearing in the abstracts of articles published in communication journals?

RQ2: How have (a) the prevalence of individual topics and (b) the associations between pairs of topics appearing in communication abstracts evolved over time? 
In addition, we have reason to believe that topics may differ in prevalence across international, national, and regional journals. Regional communication journals are generally less likely to be cited than NCA and ICA journals (Funkhouser, 1996; Keating et al., 2019) as well as less likely to be cited in NCA and ICA journals (Rice et al., 1988). Regional journals rank lower in impact metrics (Levine, 2010) and are less integrated within communication journal crosscitation networks (Borgman \& Rice, 1992; Griffin, Bolkan, Holmgren, \& Tutzauer, 2016). Differences also exist in citation rates between ICA and NCA journals, with ICA journals being less likely to cite NCA journals than NCA journals are to cite ICA journals (Leydesdorff \& Park, 2007). Levine (2010) concluded that both regional and NCA journals have experienced a recent decline in impact, whereas ICA journals remained high and continued to increase in impact.

The differences in citation patterns consistently reported among NCA, ICA, and regional journals suggest the possibility that the content published in these outlets is marked by different themes. It may be that journals sponsored by these three organizations publish articles about substantively different topics that vary in the degree to which they contribute to prevalent academic conversations. Indeed, despite many of these journals advertising as having broad topical aims, Rogers (1999) categorized NCA and regional journals (i.e., Communication Monographs, Quarterly Journal of Speech, Communication Education, and Communication Studies) as predominantly publishing articles interpersonal in nature, whereas ICA journals focused both in interpersonal (i.e., Human Communication Research) and mass media (i.e., Journal of Communication) topics. We pose the following research question to examine how the journals published by these organizations differ in the topics that recur in their article abstracts.

RQ3: What differences exist among the topics appearing in article abstracts published in regional, national, and international communication journals? 


\section{Method}

We used topic modeling to examine abstracts from over 20,000 articles published in NCA, ICA, and regional journals. Topic modeling is a form of machine learning that makes identifying structures in a sample of texts possible (for review, see Blei, 2012; Mohr \& Bogdanov, 2013). We used latent Dirichlet allocation (LDA), which involves identifying patterns of co-occurring words within individual texts to infer latent content—called topics—across a corpus of texts (Blei, 2012; Maier et al., 2018). In this project, LDA produced a list of cooccurring terms to represent topics appearing in the sample of abstracts. We then assigned labels to topics and validated them by manually verifying their presence in article abstracts. Because topics are thematic objects of focus driving individuals' attention and effort in ways that influence their goals and interests (Palomares, Bradac, \& Kellermann, 2006), assessing the topics of communication publications is a worthwhile means to understand what communication scholars have emphasized and investigated in their work.

\section{Data}

We first identified all journals sponsored by NCA, ICA, and regional communication associations as of 2015 that were dedicated to publishing original scholarly research. A total of 22 journals were identified: $\mathrm{NCA}(n=9)$, ICA $(n=6)$, and regional communication associations $(n=7)$. Table 1 includes a list of all journals in the sample. Communication and Mass Media Complete database was used to extract the citation information and abstract for every available article published in each of the 22 journals. These data were collected from the first issue of each journal through 2015. In those instances when issues of a journal were not in this database, Scopus was used as an alternate source. 
Topic Modeling Analysis of Communication Research

Table 1

Details of the Abstract Collection Process

\begin{tabular}{|c|c|c|c|c|c|}
\hline Journal Name(s) & Years & $\begin{array}{l}\text { Years of } \\
\text { missing } \\
\text { articles }\end{array}$ & $\begin{array}{l}\text { Years of } \\
\text { missing } \\
\text { abstracts }\end{array}$ & $\begin{array}{l}\text { Number } \\
\text { of } \\
\text { abstracts } \\
\text { recovered }\end{array}$ & $\begin{array}{l}\text { Number of } \\
\text { abstracts } \\
\text { included in } \\
\text { analyses }\end{array}$ \\
\hline \multicolumn{6}{|l|}{ NCA journals } \\
\hline $\begin{array}{l}\text { Communication \& Critical/Cultural } \\
\text { Studies }\end{array}$ & $2004-2015$ & None & None & 354 & 324 \\
\hline $\begin{array}{l}\text { Communication Education } \\
\text { (formerly: The Speech Teacher } \\
\text { [1952-1975]) }\end{array}$ & $1952-2015$ & None & None & 4674 & 2230 \\
\hline $\begin{array}{l}\text { Communication Monographs } \\
\text { (formerly: Speech Monographs } \\
\text { [1934-1975]) }\end{array}$ & $1934-2015$ & None & None & 2048 & 1913 \\
\hline $\begin{array}{l}\text { Critical Studies in Media } \\
\text { Communication (formerly: Critical } \\
\text { Studies in Mass Communication } \\
\text { [1984-1999]) }\end{array}$ & $1984-2015$ & None & None & 1044 & 855 \\
\hline $\begin{array}{l}\text { First Amendment Studies } \\
\text { (formerly: Speech Association of } \\
\text { America: Committee on Freedom of } \\
\text { Speech-Yearbook [1960-1969]; } \\
\text { Free Speech Yearbook [1970- } \\
\text { 2012]) }\end{array}$ & $1960-2015$ & $1960-2010$ & $1960-2010$ & 51 & 41 \\
\hline $\begin{array}{l}\text { Journal of Applied Communication } \\
\text { Research }\end{array}$ & $1973-2015$ & None & None & 872 & 764 \\
\hline $\begin{array}{l}\text { Journal of International \& } \\
\text { Intercultural Communication }\end{array}$ & $2000-2015$ & None & None & 137 & 102 \\
\hline $\begin{array}{l}\text { Quarterly Journal of Speech } \\
\text { (formerly: The Quarterly Journal of } \\
\text { Public Speaking [1915-1917]; } \\
\text { Quarterly Journal of Speech } \\
\text { Education [1918-1927]) }\end{array}$ & $1915-2015$ & None & $1915-1917$ & 11399 & 3924 \\
\hline $\begin{array}{l}\text { Text and Performance Quarterly } \\
\text { (formerly: Literature in } \\
\text { Performance [1980-1988]) }\end{array}$ & $1980-2015$ & None & None & 1281 & 741 \\
\hline
\end{tabular}


Topic Modeling Analysis of Communication Research

Regional journals

Communication Quarterly

(formerly: Today's Speech [19531975])

Communication Research Reports

$1984-2015$

None

None

1101

1086

Communication Reports

$1988-2005$

None

None

355

351

Communication Studies (formerly:

Central States Speech Journal

1949-2015

None

1949-1990

697

661

[1949-1988])

Qualitative Research Reports in

Communication

2000-2015

None

None

171

166

Southern Communication Journal (formerly: Sothern Speech Bulletin [1935-1942], The Southern Speech Journal [1942-1971]; Southern Speech Communication Journal [1971-1988])

Western Journal of Communication (formerly: Western Speech [19371974]; Western Speech Communication [1975-1976]; $1937-2015 \quad 1970-1976 \quad 1970-1976$ 2975 1644

Western Journal of Speech Communication [1977-1991])

\section{ICA journals}

Annals of the International Communication Association (formerly: Communication 1978-2015 1982-1987; 1982-1987; 414 408 Yearbook [1978-2015])

Communication, Culture \& Critique

Communication Theory

2008-2015 2010-201

2010-2015

60 56

Human Communication Research 1991-2015

None

None 427 424

Human Communication Research
$1974-2015$

None

None

980

969

Journal of Communication

1951-2015

None

1951-1987

2044

1221

Journal of Computer-Mediated Communication

1995-2010

None

None

720 707

Note. Years of missing articles refers to those years for which articles were not available in the electronic databases. Years of missing abstracts indicates those years in which articles were available but did not include an abstract or abstracts were not retrievable. 
As reported in Table 1, abstracts were available for most articles published in the 22 journals from their beginnings through 2015. We were able to locate article information, on average, for $92 \%$ of the years the 22 journals had been published. For the 40,967 articles that could be accessed, abstracts were available for $87 \%(n=35,474)$. A review revealed many brief entries ( $<4$ pages) dedicated to book reviews, announcements, and related types of contributions (e.g., editorials, corrections, etc.). Because we are interested in original communication scholarship, we attempted to exclude non-research contributions by limiting the sample to abstracts from articles greater than three pages in length. We attempted to further exclude the abstracts for articles that were greater than three pages but explicitly labeled as a book review, movie review, play review, or other type of review that was not original research (e.g., software review). A total of 14,777 articles and corresponding abstracts were excluded. Another 33 abstracts $(0.2 \%$ of the final sample) were excluded due to a technical error. The final sample included 20,664 article abstracts.

We recorded the publication outlet and publication year for each article abstract. Publication outlet was determined based on the organization sponsoring the journal: ICA ( $n=$ $3,785)$, NCA $(n=10,894)$, and the four main regional associations $(n=5,985)$ in the United States (i.e., Central States, Eastern, Southern States, and Western States Communication Associations). We used the year an article was published to assign abstracts to one of eight time periods. Consolidating abstracts into time periods was necessary to examine changes in topic prevalence over time. As noted in the literature review, the founding of ICA during the 1950s represented a watershed moment in our field. We used this date as benchmark for constructing the eight time periods. Articles published between 1918 and 1949 were consolidated into one group. The remaining articles published between 1950 and 2015 were grouped by decade. This 
metric was selected in order to balance our desire to extract nuance from the data with concerns about the potential for information overload.

\section{Procedures for Data Analysis}

Data analysis proceeded in a series of steps and generally followed the guidelines for topic modeling in communication research offered by Maier et al. (2018): preprocessing, model selection, and topic labeling and validation. After validating topics, differences over time and based on publication outlet were examined. A workflow with key steps for data analysis appears in Figure 1. The data and R script for this project are available at the following link: https://osf.io/cyfd7/?view_only=e21dd3ef21d94ac2ba49e55a7a98a2b1

Preprocessing. The first step involved preparing the data for analysis. We used the quanteda package (Benoit, 2018) in R to apply the following transformations in the exact order presented. The data were tokenized (i.e., separated into distinct words), converted to lowercase letters, and numbers and symbols were removed. Stop words were then removed and the data were stemmed. Stop words include frequently occurring words that tend not to be meaningful on their own such as propositions, articles, and similar types of words. Removing stop words was important to ensure that the abstracts were limited to substantively meaningful words. Stemming is important to reduce the size of the dataset by identifying common root words (e.g., “communication," “communicate," and "communicating” all become "communicat”). A document term matrix was then created. Following Maier et al. (2018), terms that appeared in more than $99 \%$ of documents or less than $0.5 \%$ of documents were excluded.

Model selection. The second step involved identifying the optimal number of topics for the model. We randomly partitioned the data into two subsamples with $50 \%$ in a training set and $50 \%$ retained for a validation set. Partitioning the data made it possible to use the training set to 
Figure 1. Work Flow for Sample Acquisition and Data Analyses

Data acquisition

- We manually extracted article abstract for 22 journals from their first issues through 2015.

- The sample was limited to 20,664 abstracts representing original research.

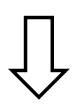

Preprocessing

- We converted abstracts to lowercase, removed numbers and symbols, removed stop words, and stemmed all words.

- Removing stop words omits high frequency words that are not substantively important (e.g., prepositions, articles, etc.) and helps restrict the sample to meaningful words.

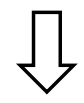

Model selection

- We divided the sample into a training and test set.

- We used LDA to test models of 2, 5, 10, 20, 40, 60, 80, 150, and 200 topics on the training set. The model with 200 topics was selected because it had the lowest perplexity score and offered most granular topics.

- We used LDA to replicate the model with 200 topics on the test set to demonstrate reliability.

- We ran the model with 200 topics on full data set.

\section{\}

Topic labeling and verification

- Two researchers independently reviewed the 10 top terms for each of the 200 topics and assigned labels.

- The two researchers met to resolve discrepancies in labeling.

- A third researcher attempted to validate the topics and labels by examining abstracts in which each topic was likely to appear.

- A total of 160 topics were deemed acceptable and used in the remaining analyses.

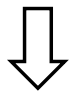

Analyses conducted to answer the research questions

- We examined the prevalence of topics over time and across the three types of journals.

- We identified the topics with greatest net cumulative increase and decrease as well as pairs of topics most likely to co-occur.

- We identified the topics with greatest differences in prevalence across the three journal types. 
identify a model and the test set to demonstrate the reproducibility of that model. Following general norms for topic modeling (Maier et al., 2018), we then identified a series of ten values representing the number of topics to be extracted. The number of topics $(\mathrm{k})$ we identified systematically varied as follows: 2, 5, 10, 20, 40, 60, 80, 100, 150, 200.

Again, the goal of the model selection step was to identify the optimal number of topics. Accordingly, we used the topicmodels package (Grün \& Hornik, 2011) in R to test ten models that only differed in the number of topics extracted based on the previously-identified series of values (e.g., 2, 5, 10, 40, etc.) We used model perplexity scores, which indicate how accurately a model predicts a sample, to compare the models. Lower perplexity scores indicate relatively greater accuracy. The perplexity scores indicated that the models with 100 topics (perplexity $=$ 587.00 ) and 200 topics (perplexity $=511.21$ ) best fit the data. The first author inspected the results of both models. The model with 200 topics best met our goal of capturing as finelygrained topics as possible and was selected.

We then used the validation dataset, which was not involved in the previous analysis, to demonstrate the reproducibility of the selected model. The model with 200 topics was tested on the validation dataset. The perplexity value was only slightly larger than with the training dataset (perplexity $=512.56$ ), offering evidence of reproducibility. Finally, the model with 200 topics was subsequently run on the full dataset with all abstracts included. The results from the full dataset were used in the remaining steps.

Topic labeling and validation. The final general step involved labeling and validating the topics in the model. The LDA analysis produced a series of terms representing each topic and a beta value reflecting each term's contribution to the topic. For example, the seven most influential terms (in stemmed form) for the third topic and their relative contributions were: 
parent (.18), children (.10), child (.08), mother (.06), adolesc (.04), adult (.03), communic (.03). Two of the authors first independently reviewed the terms with the 10 largest betas for each topic. Their goal was to determine whether a given topic was coherent based on the supplied terms and then, if it was, to apply a label reflecting the theme implied by the set of terms. For the previously-identified terms, for example, each researcher deemed the topic coherent and recommended the label "parent-child communication." It is worth reiterating that we applied the topic labels — not the LDA analysis. After completing this task independently for each of the 200 sets of terms, the authors met with the lead author to discuss the results and areas of disagreement were resolved via discussion. This process led to 174 topics being labeled and retained; 26 topics were deemed incoherent and excluded from the sample.

A third study author who was not involved in the previous steps validated the remaining 174 topics via a manual review to determine whether the topics identified in the analyses were present in the original abstracts. For each of the 174 topics, three abstracts that had a high probability of containing the topic were selected and reviewed. The goal of the review was to affirm that the topic was represented in the abstracts. Topics were deemed acceptable when they were evident in at least two of the three abstracts. Approximately $90 \%(n=158)$ of the topics were validated in reviewing the abstracts; 16 topics were not reflected in the abstracts and excluded during the validation step.

A final, more intensive review was conducted by the third author to validate our decision to exclude the 42 previously-noted topics. The goal of this final review was to ensure that these excluded topics were not erroneously removed. The third author reviewed the 20 abstracts with the highest probability of containing each of the 42 previously-excluded topics. Only two previously-excluded topics were determined to be coherent and present in original abstracts by 
the third author (i.e., "advertising features" and "communication behavior"). In sum, the topic labeling and validation process yielded the 160 validated topics reported in Table 2 . Although we grouped the validated topics into broader categories in Table 2 to facilitate interpretation, the 160 individual topics (and not the broader categories) were used in the subsequent analyses.

Evaluating differences in topics across time periods and publication outlets. For every abstract in the sample, the LDA analysis produced a gamma value reflecting the proportion of words in the abstract representing each of the 160 topics. Across the sample of abstracts, these values indicated the prevalence of topics and were used as the basis for answering the research questions. In order to answer RQ1 and identify the most prominent topics, we first determined the 50 most prevalent topics overall based on mean gamma values. We then plotted their prevalence across the eight time periods (e.g., pre-1950, 1950-59, 60-69, etc.) within each of the three types of journals (i.e., NCA, ICA, regionals) using the ggplot2 package (Wickham, 2016) for R. The results, which illustrated how the prevalence of these topics changed over time and by publication outlet, can be found in Figure 2 .

In order to answer the second research question about (a) changes in the prevalence of individual topics appearing in communication abstracts and (b) how the associations between pairs of topics evolved, we employed two respective strategies using all 160 topics. First, we used gamma values to compute the net change in prevalence for each of the 160 topics across the eight time periods. The difference in topic prevalence between adjacent time periods was computed for all topics; for example, the mean prevalence of each topic in the pre-1950 period was subtracted from the mean prevalence for the topic during the 1950-1959 period. The sum of each pairwise difference was then computed across the eight time periods. The 25 topics that experienced the greatest cumulative increase in prevalence and the 25 topics that experienced the 
Topic Modeling Analysis of Communication Research

Table 2. 160 Topics from Communication Abstracts

\begin{tabular}{|c|c|c|}
\hline Personal Relationships & $\begin{array}{l}\text { Communicators, Messages } \\
\text { Production, and Message } \\
\text { Processing }\end{array}$ & Media Use and Message Effects \\
\hline $\begin{array}{l}\text { Relationship Development } \\
\text { impression formation } \\
\text { uncertainty reduction } \\
\text { Attraction } \\
\text { mediated disclosures } \\
\text { Relationship Maintenance } \\
\text { relationship satisfaction } \\
\text { relationship maintenance } \\
\text { boundary management } \\
\text { social support } \\
\text { Conflict Management } \\
\text { expressing negative affect } \\
\text { verbal aggressiveness } \\
\text { conflict } \\
\text { topic avoidance } \\
\text { Characteristics of Relationships } \\
\text { parent-child communication } \\
\text { family communication } \\
\text { child-adult } \\
\text { romantic relationship } \\
\text { close friendships } \\
\text { patient-provider communication } \\
\text { leader-subordinate relationship } \\
\text { student-instructor communication }\end{array}$ & $\begin{array}{l}\text { Speech and Message Production } \\
\text { communication apprehension } \\
\text { language use } \\
\text { English language use } \\
\text { public speaking } \\
\text { speech anxiety } \\
\text { verbal speech characteristics } \\
\text { interpersonal goals } \\
\text { Message Processing } \\
\text { risk and efficacy } \\
\text { motivational processes } \\
\text { cognitive processing } \\
\text { responses to communication } \\
\text { listening comprehension } \\
\text { hearing } \\
\text { deception detection } \\
\text { expectancy violations } \\
\text { Decision Making } \\
\text { problem solving } \\
\text { information seeking } \\
\text { individual decision making } \\
\text { Communicator Attributes } \\
\text { source credibility } \\
\text { communicator credibility } \\
\text { communicator attributes } \\
\text { attributional style } \\
\text { interpersonal communication } \\
\text { competence }\end{array}$ & $\begin{array}{l}\text { Media and Technology Use } \\
\text { television viewing } \\
\text { television/radio broadcast } \\
\text { media use } \\
\text { technology use } \\
\text { internet use } \\
\text { online behavior } \\
\text { website } \\
\text { social networks } \\
\text { Mediated Message Effects } \\
\text { framing } \\
\text { violence and communication } \\
\text { body image } \\
\text { news coverage } \\
\text { gender representations } \\
\text { Persuasive Message Effects } \\
\text { persuasive message research } \\
\text { emotional appeals } \\
\text { narratives } \\
\text { strategic communication } \\
\text { knowledge and opinion change } \\
\text { beliefs and behavioral intentions } \\
\text { attitude change } \\
\text { explanations and accounts } \\
\text { communication behaviors } \\
\text { advertising features }\end{array}$ \\
\hline & $\begin{array}{l}\text { Individual Differences } \\
\text { intercultural comparisons } \\
\text { race/ethnicity } \\
\text { sex differences }\end{array}$ & \\
\hline
\end{tabular}

(Table continues.) 


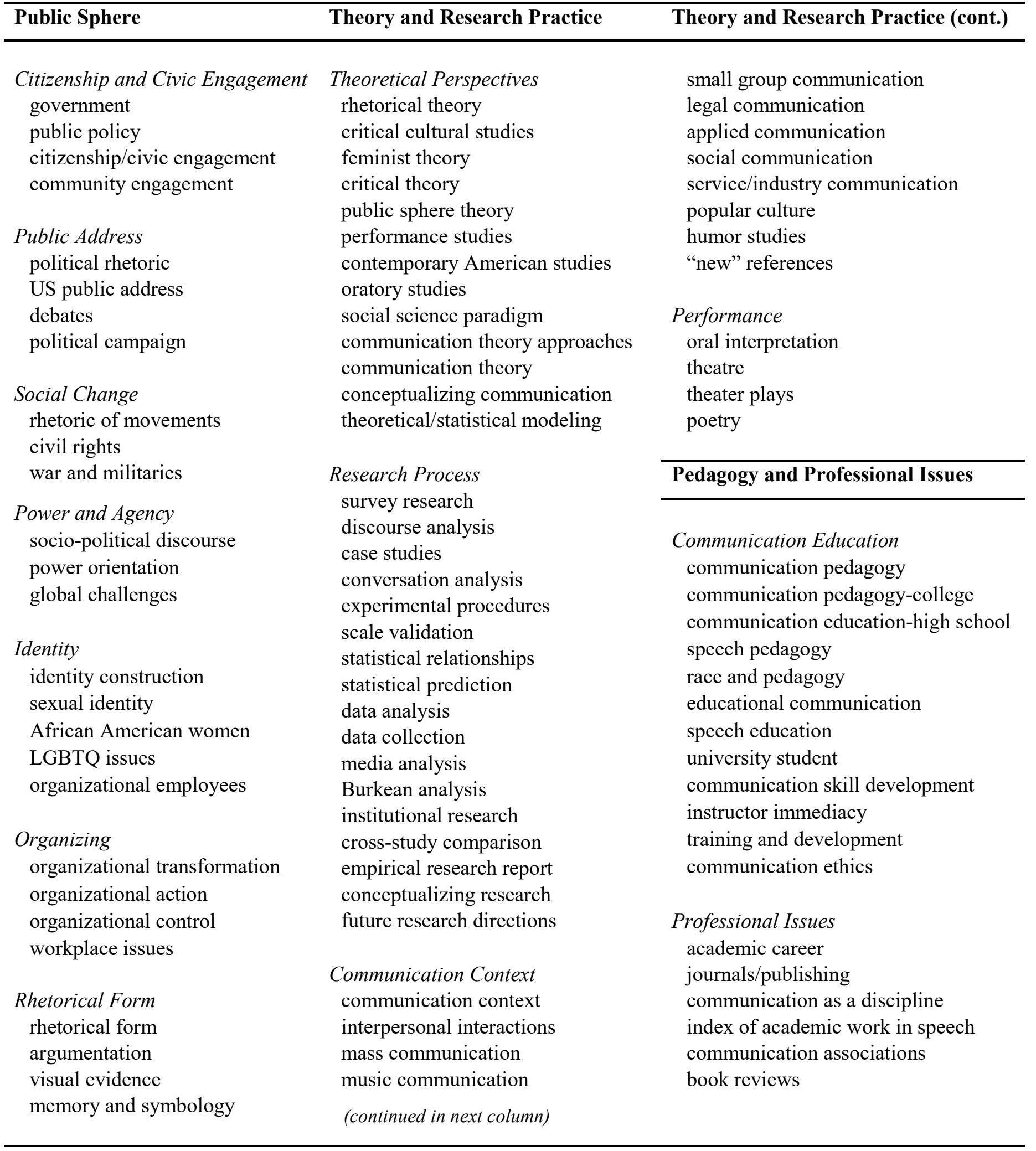

Note. The authors grouped the topics into broader categories solely to facilitate interpretation. All analyses were conducted using the 160 individual topics. 
greatest cumulative decrease in prevalence can be found in Figure 3. Second, we computed correlations in the prevalence of all possible two-topic combinations for the 160 topics. This analysis made it possible to determine the degree to which some individual topics tended to appear along with other topics in the same abstracts. Our goal was to identify the topics most likely to co-occur among all abstracts in the sample. The 25 topic pairs with the largest correlations were then plotted across the eight time periods. These data, which can be found in Figure 4, demonstrated how the co-occurrence of topics in the sample of abstracts evolved. Finally, in order to answer the third research question about differences across journal types, we first computed the mean prevalence scores for all 160 topics within each category of journal (i.e., NCA, ICA, regionals). We then computed pairwise differences in topics between the three categories of journals. The 25 topics with the largest absolute differences in prevalence between pairs of journals were then plotted in Figure 5. This figure illustrated those topics that were most likely to appear in one category of journal (e.g., ICA journals) than another journal category (e.g., NCA journals).

\section{Results}

\section{Topics Animating Communication Research}

RQ1 asked about the most prominent topics appearing in communication journal abstracts. Figure 2 reports the 50 most prevalent topics in decreasing order of occurrence and their changes over time and across journal types. These recurrent topics distinguish the issues of historical import to communication scholars. We noted four broader themes that account for the majority of the 50 most prevalent topics.

First, topics related to communication education prominently appeared throughout Figure 2, including speech pedagogy (ranked 1), speech education (2), public speaking (6), 
Figure 2. 50 Most Prevalent Topics Over Time and Across Journal Types

Change in Prevalence Over Time and Across Journal Types for Top 50 Topics
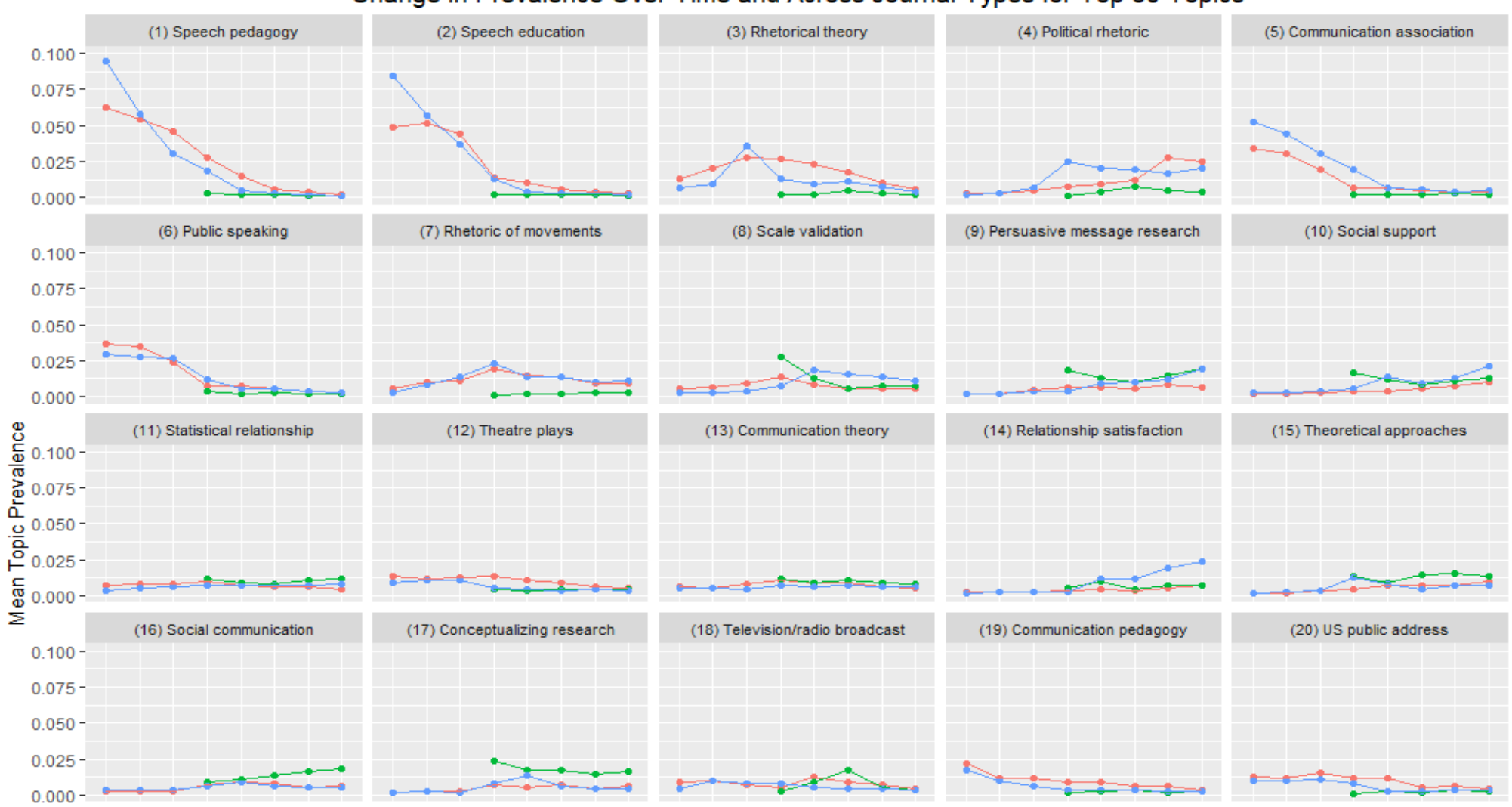

Journal Type

$\rightarrow$ NCA

$\rightarrow$ ICA

(19) Communication pedagogy

(20) US public address

$\rightarrow$ Regional

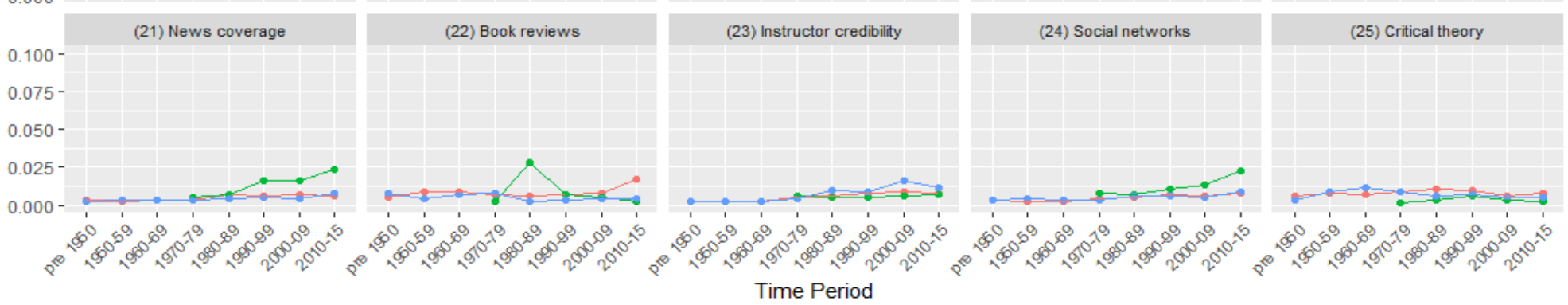

(figure continues) 


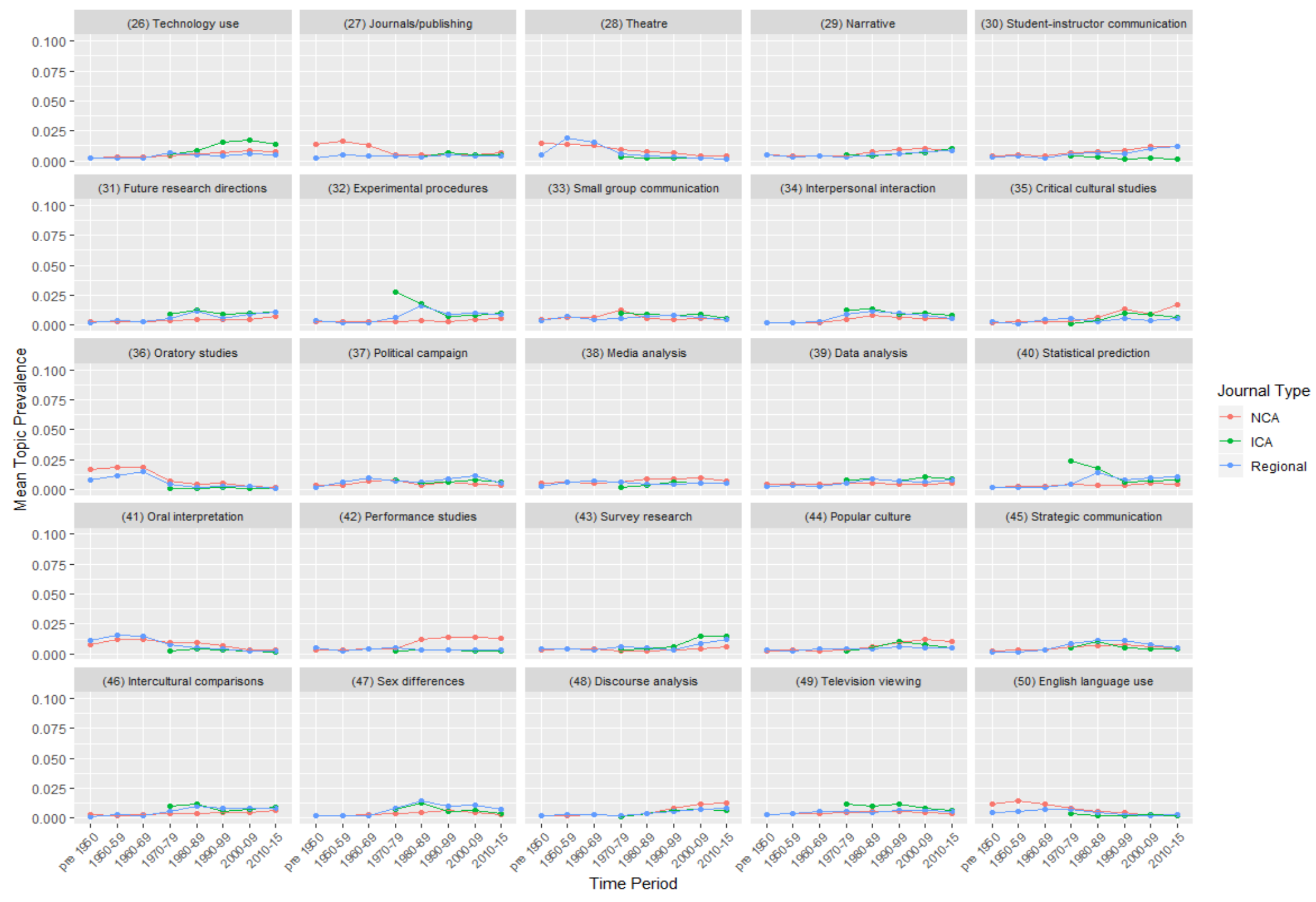


communication pedagogy (19), instructor credibility (23), and student-instructor communication (30). These topics and their relatively high rankings reflect the origins of our field in speech instruction and continued scholarly interest in pedagogical issues. Second, topics having to do with rhetorical studies were also common. Rhetorical theory (3), political rhetoric (4), rhetoric of movements (7), US public address (20), oratory studies (36), oral interpretation (41), and discourse analysis (48) all point to the centrality of rhetoric to the study of communication.

A third group related to issues associated with empirical research practices. These topics included scale validation (8), statistical relationships (11), conceptualizing research (17), future research directions (31), experimental procedures (32), data analysis (39), and statistical prediction (40). This group shows the importance of social scientific research as formative to communication scholarship. Fourth, topics interpersonal in nature also recurred. These topics included social support (10), relationship satisfaction (14), social communication (16), social networks (24), small group communication (33), interpersonal interaction (34), intercultural comparisons (46), and sex differences (47). This serves as the final large group of prominent topics to emerge from our analysis.

\section{Topic Prevalence Over Time}

RQ2a inquired about how the prevalence of individual topics appearing in communication abstracts has changed over time. Figure 3 reports the 25 topics with the greatest cumulative net increase in prevalence over time and the 25 topics with the greatest cumulative net decrease in prevalence. Several trends were apparent when reviewing this figure along with Figure 2. One noteworthy trend involved the marked decrease in scholarly treatment of issues associated with speech education. Although this was the most prominent topical theme appearing in Figure 1, the results in Figure 2 indicated that it also lost the most scholarly attention over 
Figure 3. Topics with Greatest Net Cumulative Change Over Time

Topics with Greatest Cumulative Change in Prevalence Over Time

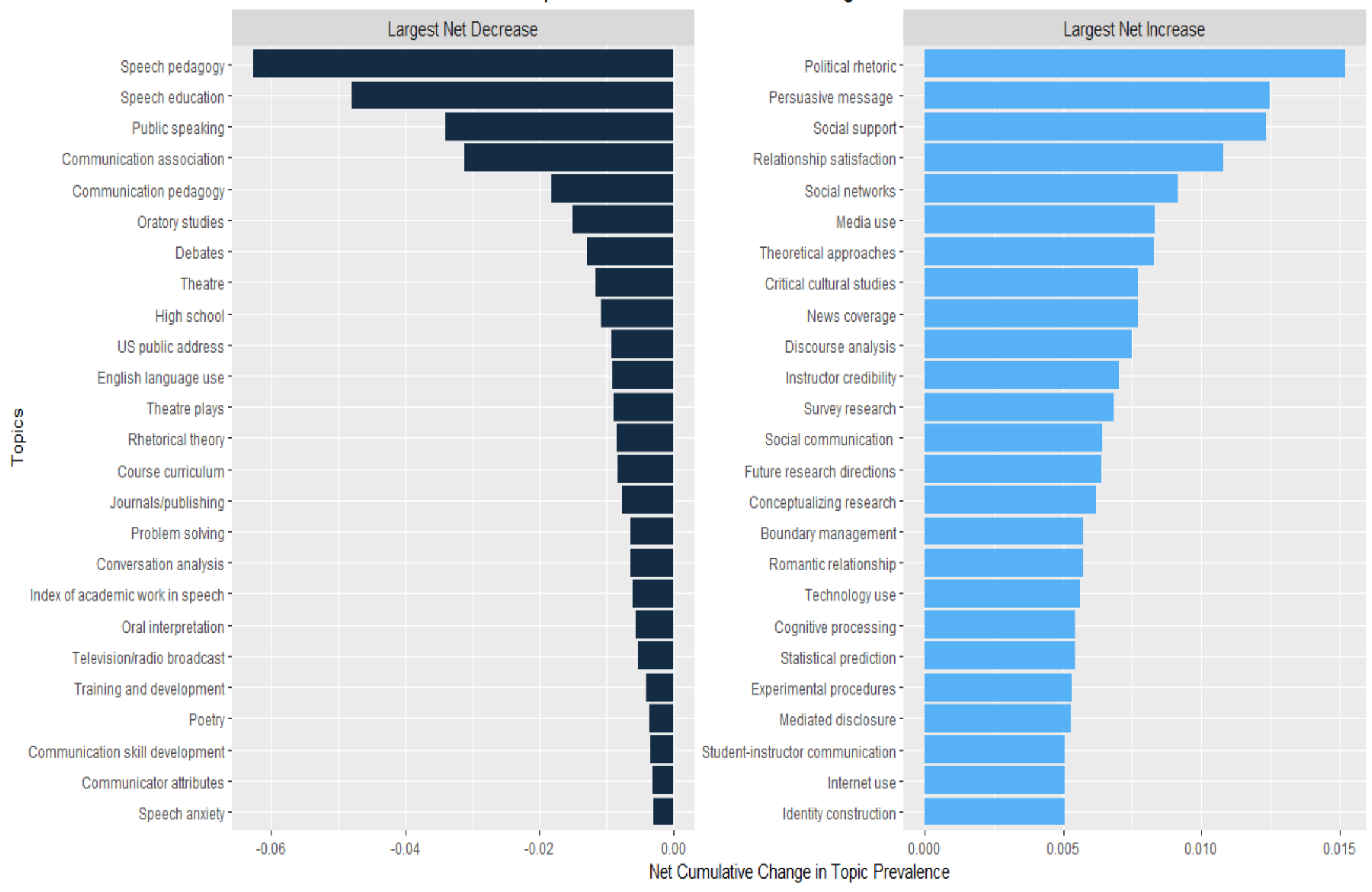


time. Topics such as speech pedagogy, speech education, and public speaking were more common during earlier decades. Of the 25 topics with the greatest net decrease, at least one-third related to pedagogical issues. Other topics that experienced a decline reflect conversations central to the field's inception, such as topics of debate and theatre, as well as those important to the field's growth and development, such as the topics of communication association and journals/publishing.

A number of topics have become more prevalent over time. The topic of political rhetoric experienced the greatest cumulative growth. Topics related to interpersonal processes (e.g., relationship satisfaction, social support, romantic relationship), social influence (e.g., credibility, persuasion, political rhetoric), and technology (e.g., media use, technology use, internet use) also increased over the years. Issues associated with general research practices (e.g., future research directions, conceptualizing research) as well as specific research methods, both quantitative (e.g., survey research, statistical prediction, experimental procedures) and qualitative (e.g., discourse analysis), also increased in prevalence. Despite an overall decline in topics associated with speech pedagogy, topics associated with relational aspects of communication education (e.g., instructor credibility, student-instructor communication) experienced some increase. Coupled with decreased attention to speech education and public speaking, this finding points to the field's increased focus on knowledge accumulation and theory building at the expense of work concerning praxis and pedagogy.

RQ2b focused on the evolution of topics co-occurring in communication abstracts over time. Figure 4 reports temporal changes in the magnitude of correlations for the top 25 correlated topic pairs. Topic pairs (1-25) have been presented in descending order from relatively strongest to weakest overall correlation across the entire dataset. Several themes were evident in topics 
Figure 4. Associations for the Top 25 Co-Occurring Pairs of Topics Over Time

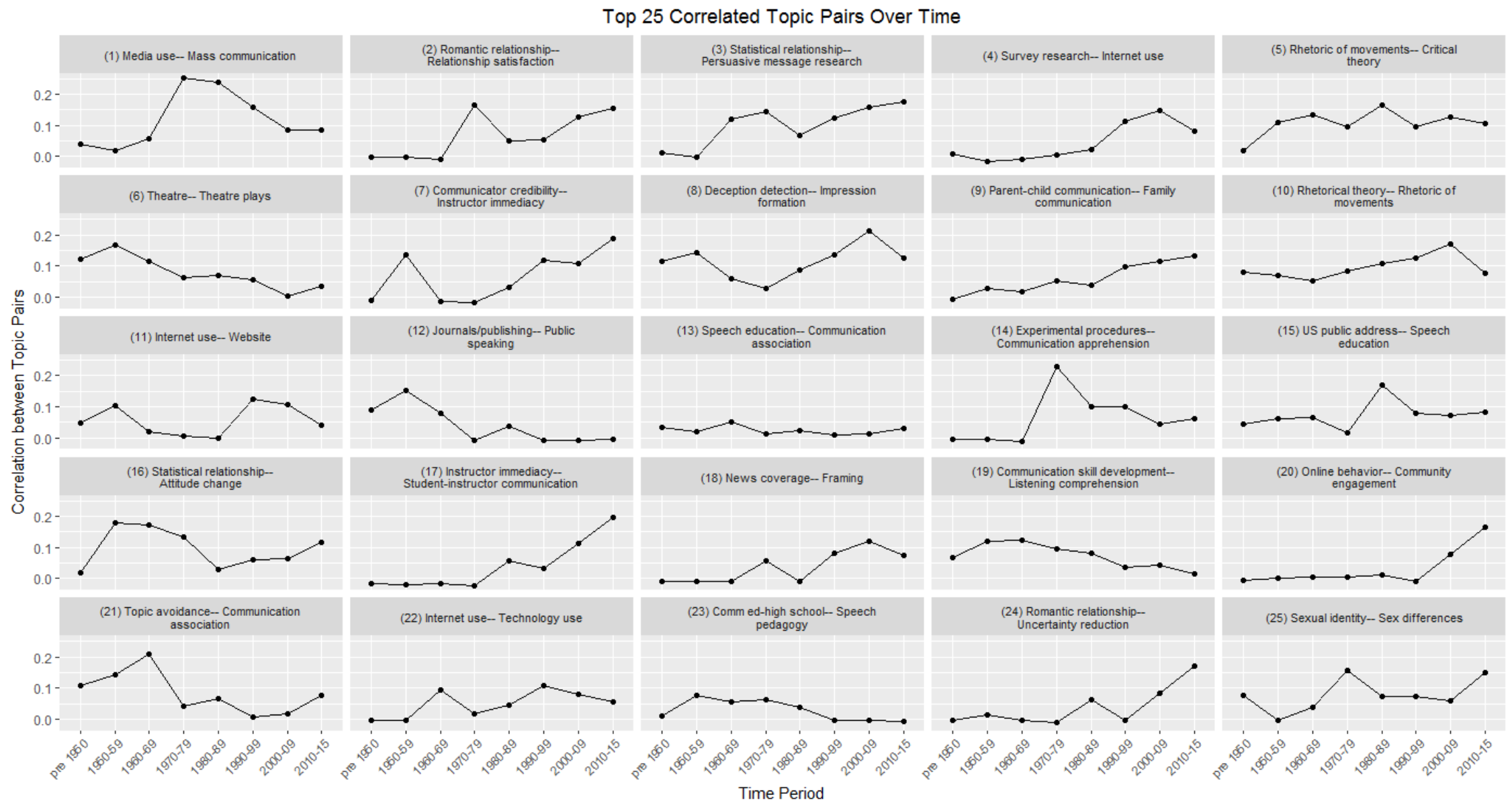


that were correlated over time. The five most strongly correlated topic pairs included a focus on media use and mass communication (ranked 1), romantic relationships and relational satisfaction (2), statistical relationships and persuasive message research (3), survey research and internet use (4), and rhetoric of movements and critical theory (5).

Changes in the magnitude of topic-pair correlations over time demonstrate how that the field has evolved. Topic pairs representing speech communication and pedagogy trended toward a decrease over the 8 time periods (e.g., theatre and theatre plays; journals/publishing and public speaking; communication skill development and listening comprehension). Topic pairs reflecting empirical methods and media, in contrast, were increasingly likely to co-occur over the eight time periods (e.g., statistical relationship and persuasive message research; survey research and internet use; news coverage and framing; online behavior and community engagement).

\section{Topic Prevalence Based on Journal Type}

RQ3 asked about differences in topic prevalence across NCA, ICA, and regional communication journals. The 25 topics with the greatest discrepancies in prevalence between pairs of journals can be found in Figure 5. Several trends were evident in the prevalence of topics across journal types.

A number of topics were most likely to appear in one of the three types of journals. Topics involving pedagogy and public speaking were most common in NCA journals. These topics included speech pedagogy, speech education, communication pedagogy, public speaking, US public address, oratory studies, and rhetorical theory. In ICA journals, topics related to research practices (e.g., conceptualizing research, theoretical approaches, experimental procedures, survey research) were most prevalent as well as topics related to media research (e.g., news coverage, internet use, technology use, media use) and focused topics like social 
Figure 5. Difference in Topic Prevalence Across Three Journal Types

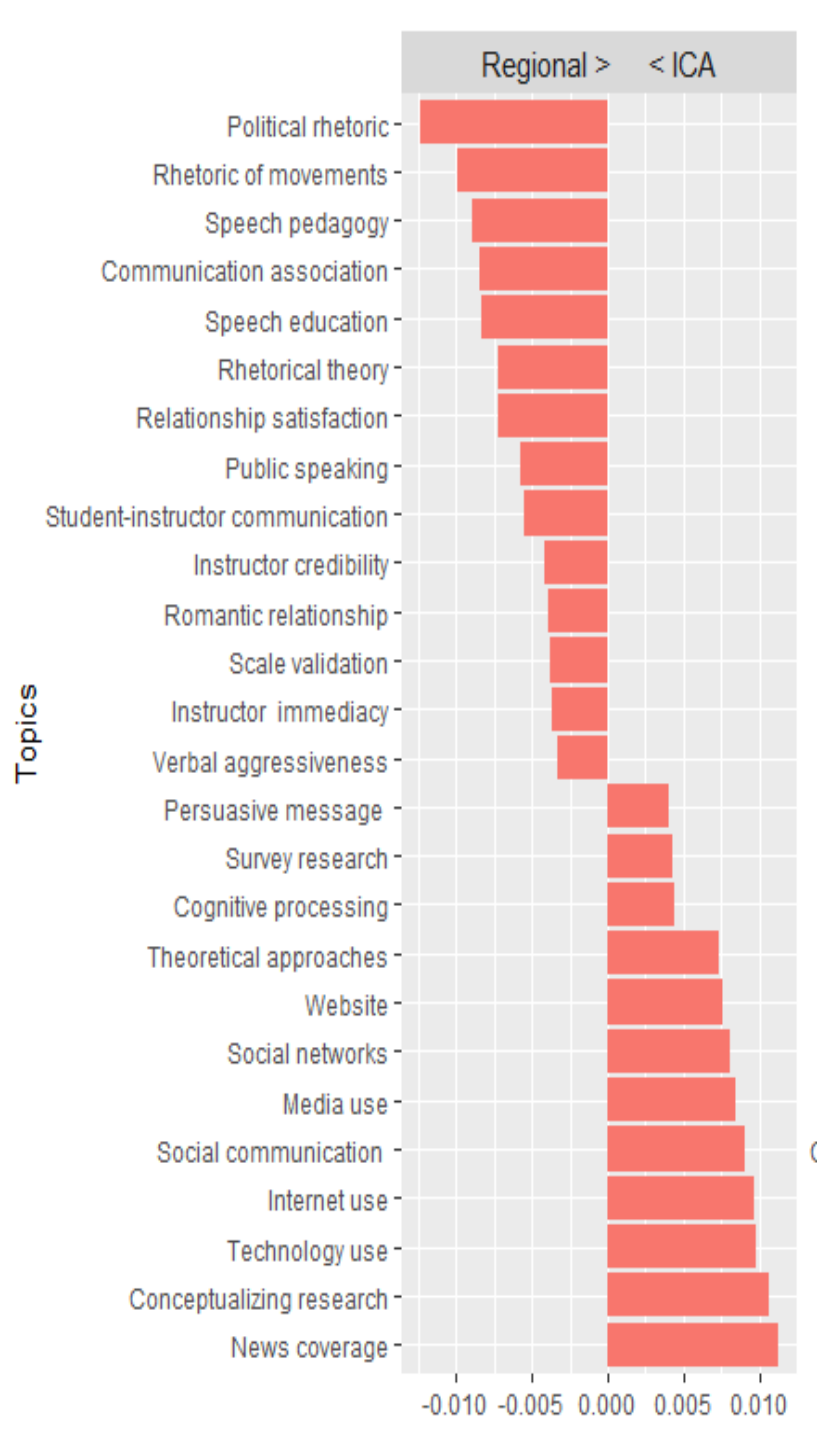

\section{Difference in Topic Prevalence Between Journal Types}

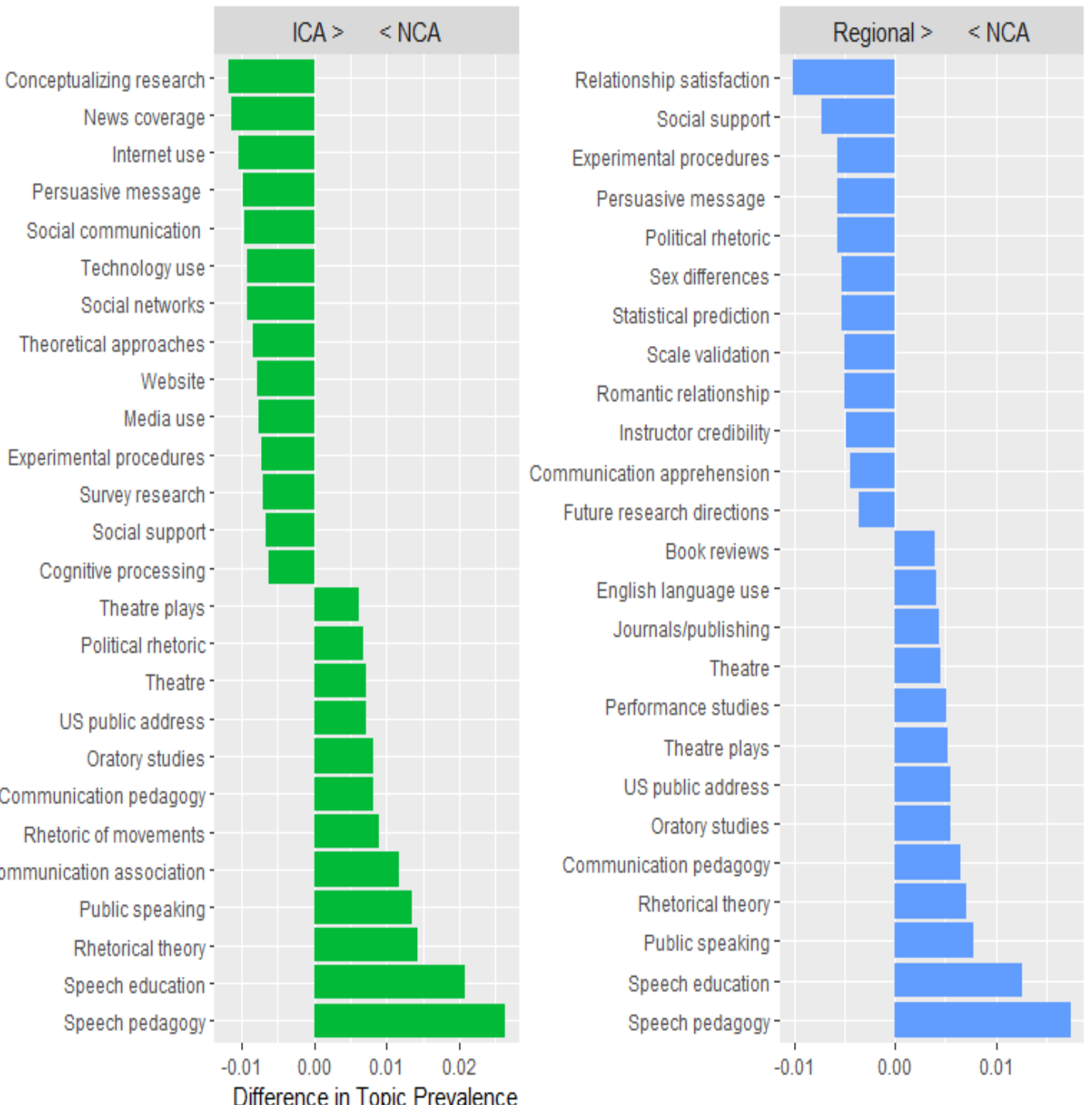


networks. Few topics were most prevalent among regional journals (e.g., political rhetoric, relationship satisfaction, and instructor credibility). Most notably, several topics related to quantitative methodology were more likely to be found in regional journals (e.g., scale validation, experimental procedures, statistical prediction) than NCA or ICA journals.

\section{Discussion}

The dramatic growth in communication scholars and scholarship during the past century has raised important questions about what it means to study human communication (Eadie, 2011; Swanson, 1993; Wartella, 1996). Although narrative histories (e.g., Delia, 1987; Dennis \& Wartella, 1996; Sherry, 2004) and empirical examinations (e.g., Günther \& Domahidi, 2017; Song, Eberl, \& Eisele, 2020) have attempted to answer them, the current study offers a comprehensive look at the field that is data-driven and more expansive than previous works. We present a descriptive account of the topics that animate communication research by examining the abstracts from more than 20,000 articles published in 22 communication journals between 1918 and 2015. The results underscore the complex and changing nature of our field. Rather than serving as a replacement, we believe this project complements and expands on previous efforts to document the history of our field. We consider the state and evolution of communication scholarship in the following paragraphs.

\section{The Current State of Communication Scholarship}

Trends among the 50 most prevalent topics appearing in article abstracts since the beginnings of our field provide insight about the state of communication scholarship. The observed topics in Figure 2 coalesced around several broader themes, with the primary ones involving communication education, rhetorical studies, empirical research practices, and interpersonal issues. To a lesser degree, topics associated with media and technology, critical and 
cultural approaches, public persuasion, professional issues, and theatre were prevalent. These themes in prevalent topics highlight the diversity that marks communication scholarship. Research published in communication journals addressed a wide variety of issues from personal relationships and media effects to the public sphere and pedagogy. This diversity is also evident in the topics addressing a variety of metatheoretical perspectives ranging from rhetorical theory and critical theory to the social science paradigm as well as research methods from surveys to discourse analysis. In their narrative history of American communication research, Dennis and Wartella (1996) note that the lack of theoretical cohesion in our field may be part of the maturation process of an (relatively) young intellectual discipline.

The results displayed in Figures 2 and 5 underscore the role of major scholarly organizations in contributing to the diversity of our field. Figure 5, in particular, indicates that topics related to speech, rhetoric, and pedagogy were more prevalent in NCA journals than ICA journals. Topics related to media, social influence, and research practice were more prevalent in ICA journals than NCA journals. This set of findings highlights the unique histories of NCA and ICA as communication organizations. As an outgrowth of the National Association of Academic Teachers of Public Speaking, it is not surprising that topics related to speech pedagogy and public speaking were more prevalent in NCA journals. ICA was established in the early 1950s in an effort to cultivate social scientific research (Weaver, 1977). Given the historical and international interest in mass media (e.g., Dennis \& Wartella, 1996; Lowery \& DeFleur, 1995; Rice et al., 1996; Rogers, 1994; Schramm, 1997), it makes sense that ICA journals would publish more research related to media. The agendas that motivated the creation of these two organizations appear to have had a lasting impact on the scholarship published in the journals they sponsor. Along the same lines, topics related to quantitative research methodology 
distinguished regional journals from ICA and NCA journals. The greater prevalence of topics like scale validation, experimental procedures, and statistical prediction in regional journals may stem from a larger premium being placed on theoretical contributions than methodological contributions in ICA and NCA journals.

The diversity of research foci and approaches has been hailed as both a key strength and limitation of communication scholarship. Swanson (1993), for example, argued that fragmentation prevents us from being a discipline but also leaves us unencumbered by disciplinary dogma that stifles innovation. Our data are consistent with this idea. Diversity in topics across communication research is beneficial for interdisciplinary reasons and encouraging multiple perspectives and methods. Communication research examines assorted phenomena in a variety of ways to generate a heterogeneous body of knowledge.

At the same time, our data suggest that the fragmentation of communication scholarship might also be problematic in some ways. The topic pairs with the strongest correlations reported in Figure 4 reflect scholars working within subfields like interpersonal communication (e.g., romantic relationship and relationship satisfaction), media (e.g., media use and mass communication), or rhetoric (e.g., rhetorical theory and rhetoric of movements) rather than across subfields. The fragmentation of the discipline coupled with increased growth suggests the potential for more and more disjointed subgroups. Over time, this splintering could lead to a complete break. In the same way that the National Society for the Study of Communication was founded by researchers who wanted to move beyond the study of speech and rhetoric (Weaver, 1977), it is not difficult to imagine new organizations dedicated to promoting and developing only part of our present discipline. Indeed, interdisciplinary associations that are unaffiliated with NCA or ICA, such as the Rhetoric Society of America and International Association for 
Relationship Research, arguably are at least in part an artifact of fragmentation. Such splintering, however, is not inevitable. For instance, Song et al. (2020) found that recent communication science research has been characterized by a mixture of specialization and integration, suggesting linkages occur more frequently than might be expected. As communication scholars, we can identify shared interest and engage in meaningful collaboration across relatively disconnected subareas.

Despite the diversity of topics appearing in communication journal abstracts, three noteworthy constants were evident among the 50 most prevalent topics reported in Figure 2 regarding how we have inherently conceptualized communication. Communication is a process involving the exchange of meaning and information across contexts and modes of interaction. Indeed, a number of the most prevalent topics centered around processes of messages and message exchange - either explicitly (as in the case of persuasive message research, narrative, interpersonal interaction, news coverage, and strategic communication) or implicitly (as in the case of instructor credibility, political campaign, and television viewing). Such fundamental communication processes regarding how people exchange messages are central to our field, and these data confirm our field's commitment to message-related phenomena. Many of the founding figures (e.g., Lazarfeld) identified in narrative histories of communication were from other disciplines like psychology or sociology, and their focus on messages and message effects caused them to help establish a new field emphasizing the same issues (Rogers, 1994). Communication has since carved out a niche for itself among our sibling disciplines and solidified our unique identity by focusing on message-related processes in a diverse set of contexts. 
A second constant in the 50 most prevalent topics involves the significance of pedagogy as a primary domain in which to examine how people exchange messages. Topics like speech pedagogy, speech education, and communication pedagogy reflect our genesis from an organization dedicated to teaching public speaking (O’Neil, 1915). The prevalence of topics addressing more relational facets of instruction like student-instructor communication and instructor credibility underscore the field's enduring commitment to teaching, but also its increasing foci on fundamental communication processes as the discipline grew. These data collectively offer evidence that the scholar-teacher model is a longstanding value in our discipline that persists as a meaningful context in which to examine message exchange and related processes.

Third, the 50 most prevalent topics represented unique communication contexts (relational, cultural, technological, methodological, etc.) to a greater extent than they reflected core communication processes of message exchange. Relatively few topics reflected efforts to understand fundamental patterns of message production, exchange, or effects in ways that transcend subareas of communication. Consulting topics beyond the top 50, which are reported in Table 2, is even more telling. A majority of the 160 topics we identified focus on specific relationships (e.g., parent-child, romantic, close friend, student-instructor, and doctor-patient relationships), technologies (e.g., television/radio broadcast, website), cultures and identities (e.g., sexual identity, popular culture, sex differences, African American women), modes and venues of communication (e.g., debates, poetry, theatre, music communication, legal communication), and other concentrated interests. Such foci are not surprising given the contextually-dependent divisional nature of our major organizations that privilege separate and distinct domains of scholarship. ICA, for example, was conceived with four primary research 
tracks dedicated to interpersonal, mass, organizational, and information systems (Weaver, 1977). Although there is undoubtedly value in such structures, one unintended consequence may be the tendency to encourage scholarship focused more on context rather than fundamental communication processes. We return to this issue in considering the evolution of communication scholarship.

\section{The Evolution of Communication Scholarship}

The data reported in Figures 2-5 also offer insights about the evolution of communication scholarship. In considering these findings, it is important to note that the LDA model was time insensitive. By including all of the abstracts from the sample in that analysis, we assumed that each topic identified could have theoretically existed in communication abstracts at any time period between 1918 and 2015. This approach ensured that our over-time analyses are not biased by the number of topics addressed during any single period.

At the broadest level, the figures collectively underscore what our field has largely been as well as who we might become. As previously noted, our discipline has a history of contextually-focused research involving the deployment of idiographic perspectives to study communication phenomena within specific settings, like personal relationships, media, health, or other domains. Such contextually-focused efforts have generated deep and narrow knowledge within each subfield in ways that do not take into account contexts beyond the particular setting of interest. Less frequently, communication scholars have emphasized a process-oriented understanding of human communication that highlights how central processes - such as persuasion - fundamentally function within and across subdomains of communication that transcend contextual subtleties in explainable, predictable, and practical ways. This perspective 
is focused on understanding general patterns of meaning and information exchange that span diverse contexts from more nomothetic positions (Huskey et al., 2020).

Our data suggest that communication scholars have not engaged in these two strategies with equal frequencies. Although attention to process-oriented phenomena appears to be increasing, topics and topic pairs emphasizing within-context phenomena were more common than contextually transcendent topics. If we want to situate our field in an optimal position and have a voice in contemporary research agendas across several domains of interdisciplinary scholarship, then we should pay heed to this self-reflected assessment. Communication is a process with many generalized regularities (Berger, Roloff, \& Roskos-Ewoldsen, 2010). As such, privileging research questions focusing on fundamental communication processes has greater potential to generate sophisticated theoretical perspectives and heuristic findings.

Efforts to study within-context phenomena have also bred insularity in communication scholarship. The most strongly correlated topic pairs reported in Figure 4 suggest that our field has not extensively examined communication processes in ways that convey cross-context considerations. The 25 most prevalent topic pairs were almost exclusively from within the same subfield (e.g., media use and mass communication, romantic relationship and relationship satisfaction). This tracks with previous work finding that citation networks often cluster into mass communication topics and interpersonal communication topics (Rice et al., 1996). Perhaps hybrid studies connecting topics in ways not present in our data are more likely to appear in specialty and/or interdisciplinary journals than the publication outlets we examined. Nonetheless, we believe that future efforts to theoretically and empirically connect infrequently intersecting topics - particularly those that reflect transcendent communication processes—-would pay dividends for our growth as a field. 
Several more specific patterns regarding the evolution of communication scholarship were evident in the figures. One obvious pattern involved an increased focus on theory and decreased attention to praxis and pedagogy. The increased focus on theory is also noted in narrative histories of the field (Dennis \& Wartella, 1996; Lowery \& DeFleur, 1995). As illustrated in Figures 2 and 3, in particular, topics like speech pedagogy, speech education, and public speaking were most prevalent prior to 1950 and experienced the greatest net decrease in prevalence over time. This trend offers evidence that the creation of speech departments during the early 1900s served as a springboard for the growth of speech education (Delia, 1987). The primary objective of communication academicians at that time was in the instruction of basic communication skills. Notably, the topic communication association was also most prevalent during this time period and among the topics that experienced the largest net decrease in prevalence over time. This finding underscores the nascent status of the discipline prior to 1950 and salience of efforts to develop organizations reflecting the shared interests of researchers at that time (O’Neil, 1915; Weaver, 1977).

The decreased prevalence of topics related to pedagogy over time was matched by the increased prevalence of topics generally involving communication theory and research. Although the increased focus on theory is encouraging, the lack of topics related to biological frameworks and explanations suggests we have been limited in our ability to answer "why" questions thus far (Huskey et al., 2020; Sherry, 2004). Further, as illustrated in Figures 2 and 4, topics (e.g., US public address, rhetorical theory, political rhetoric) and topic pairs (e.g., rhetoric of movements and critical theory) involving rhetoric increased in prevalence starting during the 1960s. Around that time, topics reflecting the introduction of various formal research methods also began appearing and subsequently experienced dramatic growth. Several of the 25 topics that had the 
largest net increase in prevalence reported in Figure 3 involve research methods (e.g., discourse analysis, survey research, experimental procedures) or empirical research practice more generally (e.g., theoretical approaches, conceptualizing research, statistical prediction). These developments highlight the introduction and maturation of social scientific methods that began following World War II (Delia, 1987).

More recent decades have been marked by the prevalence of topics related to media, technology, interpersonal communication, and critical cultural studies. As reported in Figure 3, topics like news coverage, media use, technology use, relationship satisfaction, and critical cultural studies saw the greatest net increase in prevalence over time. Some of these changesmost notably, attention to media representations and cultural studies topics - may reflect increased efforts to engage in intersectional research and highlight historically marginalized voices and experiences. Similarly, the correlations reported in Figure 4 between topic pairs like parent-child communication and family communication, news coverage and framing, as well as internet use and website were strongest during the past few decades.

Beyond broad changes in what has been studied, the results of this project offer insights about the nuances of research practices. The results displayed in Figures 2-4 indicate that communication researchers have increasingly focused on more complex phenomena surrounding the exchange of messages. Topic like persuasive message, social support, political rhetoric, boundary management, and cognitive processing were among the topics that experienced the greatest net increase in prevalence over time. These topics reflect specific social and intrapersonal processes involved in message construction, exchange, and effects. As communication research has evolved, efforts to understand the implications of messages have become more intricate. 
A final insight related to the nuances of communication research practices involves the sensitivity of communication researchers to current events. The topic co-occurrences reported in Figure 4 show spikes wherein some topic pairs have temporary influxes for a decade or two, such as sexual identity and sex differences, which spiked during the 70 s. The topics pairs involving survey research and Internet use as well as Internet use and website both spiked during the 1990s and 2000s. Moreover, the extent to which the topics of romantic relationships and uncertainty reduction co-occurred over time demonstrated a spike starting from the 2000 s, perhaps in reaction to widespread diffusion of communication technologies that have increased our potential for connection and information about our partners. These trends offer evidence that communication research has not been conducted in a vacuum. Communication scholarship has been sensitive to current events and the exigencies of contemporary life, something explicitly noted in narrative histories (Dennis \& Wartella, 1996; Lowery \& DeFleur, 1995).

\section{Limitations}

In considering the results of this study, a few limitations should be noted. One limitation involves the analyses. A primary objective for selecting the number of topics to be included in the analysis was to identify as many fine-grained topics as possible. Our goal was to capture as much nuance as possible in the sample of article abstracts. An artifact of this approach was that a number of topics were excluded during the topic-labeling and validation stages. The approaches for topic labeling and validation used in this project are consistent with best practices for topic modeling in communication research (Maier et al., 2018) and the number of topics identified was consistent with the results of related research (Günther \& Domahidi, 2017).

A second limitation involves the sample of journals we considered. Readers might understandability question our decision to include some journals and not others. Our sample was 
driven by our goal of examining the implications of major scholarly organizations for the evolution of communication scholarship. From that perspective, we believe that focusing on the journals published by major communication organizations is defensible. Beyond the legitimacy accrued by virtue of their organizational affiliation, this set of journals is representative of the breadth of our field spanning the social sciences and humanities.

Third, despite our best efforts to exclude them from the sample, a topic reflecting book reviews was identified in the analysis. The presence of this topic underscores the challenges of working with large datasets. Although we attempted to manually remove any journal article explicitly labeled as a book review or that was fewer than four pages in length, at least a few book reviews that did not meet these criteria were not excluded. Finally, in considering existing narrative histories of our field, we noted the lack of diversity among the authors of these works - they have been dominated by White, and almost exclusively male, voices. We raise this issue as a more general limitation of efforts to summarize and critique our field. We would collectively benefit from greater diversity among scholars publishing reflections on the development of our discipline.

\section{Conclusion}

The dramatic growth in the communication discipline during the past century makes reflecting on our collective progress essential. We used article abstracts published in 22 journals from 1918-2015 to examine the topics that appear in communication scholarship. The results underscore the diversity and nuance of research on human communication as well as meaningful differences in how communication has been examined over time and across different types of journals. We hope that this project presents new and seasoned scholars alike insights about the state and evolution of our discipline. Moving forward, we are optimistic that scholars will 
increasingly ask research questions focused on understanding process-oriented mechanisms of communication across (and within) a diverse range of contexts. We believe that such efforts will make particularly valuable contributions to the continued advancement of our discipline during the next century and beyond. 


\section{References}

Benoit, K. (2018). quanteda package for R [software]. Retrieved from: https://cran.rproject.org/web/packages/quanteda/index.html

Benson, T. W. (Ed.). (1985). Speech communication in the 20th century. Carbondale, IL: Southern Illinois University Press.

Berelson, B. (1959). The state of communication research. Public Opinion Quarterly, 23, 1-2. doi: $10.1086 / 266840$

Berger, C. R., Roloff, M. E., \& Roskos-Ewoldsen, D. (2010). What is communication science? In C. R. Berger, M. E. Roloff, \& D. R. Roskos-Ewoldsen (Eds.), The handbook of communication science (pp. 3-20). Thousand Oaks, CA: Sage.

Blei, D. M. (2012). Probabilistic topic models. Communications of the ACM, 55, 77-84. doi:10.1145/2133806.2133826

Borgman, C. L., \& Rice, R. E. (1992). The convergence of information science and communication: A bibliometric analysis. Journal of the American Society for Information Science, 43, 397-411. doi:10.1002/(SICI)1097-4571(199207)43:6<397::AIDASI1>3.0.CO;2-M

Bryant, J., \& Miron, D. (2004). Theory and research in mass communication. Journal of Communication, 54, 662-704. doi:10.1111/j.1460-2466.2004.tb02650.x

Bryant, J., \& Pribanic-Smith, E. J. (2010). A historical overview of research in communication science. In C. R. Berger, M. E. Roloff, \& D. R. Roskos-Ewoldsen (Eds.), The handbook of communication science (pp. 21-36). Thousand Oaks, CA: Sage.

Chakravartty, P., Kuo, R., Grubbs, V., \& Mcllwain, C. (2018). \#CommunicationSoWhite. Journal of Communication, 68, 254-266. doi:10.1093/joc/jqy003 
Chung, C. J., Barnett, G. A., Kim, K., \& Lackaff, D. (2013). An analysis on communication theory and discipline. Scientometrics, 95, 985-1002. doi: 10.1007/s11192-012-0869-4

Craig, R. T. (1999). Communication theory as a field. Communication Theory, 9, 119-161. doi: 10.1111/j.1468-2885.1999.tb00355.x

Delia, J. G. (1987). Communication research: A history. In C. R. Berger and S. H. Chaffee (Eds.), Handbook of Communication Science (pp. 20-98). Newbury Park, CA: Sage.

Dennis, E. E., \& Wartella, E. (1996). American communication research: The remembered history. Mahwah, NJ: Erlbaum.

Eadie, W. F. (2011). Stories we tell: Fragmentation and convergence in communication disciplinary history. Review of Communication, 11, 161-176. doi:10.1080/15358593.2011.578257

Feeley, T. H. (2008). A bibliometric analysis of communication journals from 2002 to 2005. Human Communication Research, 34, 505-520. doi:10.1111/j.1468-2958.2008.00330.x

Funkhouser, E. T. (1996). The evaluative use of citation analysis for communication journals. Human Communication Research, 22, 563-574. doi:10.1111/j.1468-2958.1996.tb00379.x

Griffin, D. J., Bolkan, S., Holmgren, J. L., \& Tutzauer, F. (2016). Central journals and authors in communication using a publication network. Scientometrics, 106, 91-104. doi:10.1007/s11192-015-1774-4

Grün, B., \& Hornik, K. (2011). topicmodels: An R package for fitting topic models. Journal of Statistical Software, 40, 1-30. doi:10.18637/jss.v040.i13

Günther, E., \& Domahidi, E. (2017). What communication scholar write about: An analysis of 80 years of research in high-impact journals. International Journal of Communication, $11,3051-3071$. 
Huskey, R., Bue, A. C., Eden, A., Grall, C., Meshi, D., Prena, K., .. \& Wilcox, S. (2020). Marr's tri-level framework integrates biological explanation across communication subfields. Journal of Communication, 70, 356-378. doi:10.1093/joc/jqaa007

Keating, D. M., Richards, A. S., Palomares, N. A., Banas, J. A., Joyce, N., \& Rains, S. A. (2019). Titling practices and their implications in communication research 1970-2010: Cutesy cues carry citation consequences. Communication Research. Advance online publication. doi:10.1177/0093650219887025

Keating, D. M., \& Totzkay, D. (2019). We do publish (conceptual) replications (sometimes): Publication trends in communication science, 2007-2016. Annals of the International Communication Association, 43, 225-239. doi:10.1080/23808985.2019.1632218

Knower, F. H. (1935). Graduate theses — an index of graduate work in the field of speech from 1902 to 1934. Speech Monographs, 2, 1-49. doi:10.1080/03637753509374827

Knower, F. H. (1936). Graduate theses — an index of graduate work in the field of speech—II. Speech Monographs, 3, 1-20. doi:10.1080/03637753609374839

Levine, T. R. (2010). Rankings and trends in citation patterns of communication journals. Communication Education, 59, 41-51. doi:10.1080/03634520903296825

Levine, T. R. (2013). Quantitative communication research: Review, trends, and critique. Review of Communication Research, 1, 69-84.

Leydesdorff, L., \& Park, H. W. (2007). The Journal of Communication and the field of communication studies: Mapping scientific communication online. Paper presented at the annual conference of the International Communication Association.

Lowery, S., \& DeFleur, M. (1995). Milestones in mass communication research. White Plains, NY: Longman. 
Maier, D., Waldherr, A., Miltner, P., Wiedemann, G., Niekler, A., Keinert, A. ... \& Adam, S. (2018). Applying LDA topic modeling in communication research: Toward a valid and reliable methodology. Communication Methods and Measures, 12, 93-118. doi:10.1080/19312458.2018.1430754

Miller, G. R. (1983). Taking stock of a discipline. Journal of Communication, 33, 31-41. doi:10.1111/j.1460-2466.1983.tb02403.x

Mohr, J. W., \& Bogdanov, P. (2013). Introduction-topic models: What they are and why they matter. Poetics, 41, 545-569. doi:10.1016/j.poetic.2013.10.001

National Communication Association. (2016). C-brief: Conferred degrees in communication, 1970-2014. Retrieved from: https://www.natcom.org/sites/default/files/publications/NCA_C-Brief_2016_May_I.pdf

O'Neill, J. (1915). The national association. Quarterly Journal of Public Speaking, 1, 51-58. doi:10.1080/00335631509360458

Palomares, N. A., Bradac, J. J., \& Kellermann, K. (2006). Conversational topic along a continuum of perspectives: Conceptual issues. Annals of the International Communication Association, 30, 45-97. doi:10.1080/23808985.2006.11679055

Peng, T-Q., Zhang, L., Zhong, Z-J, Zhu, J. JH. (2012). Mapping the landscape of Internet studies. Text mining of social science journal articles 2000-2009. New Media \& Society, 15, 644-664. doi:10.1177/1461444812462846

Rice, R. E., Borgman, C. L., \& Reeves, B. (1988). Citation networks of communication journals, 1977-1985: Cliques and positions, citations made and citations received. Human Communication Research, 15, 256-283. doi:10.1111/j.1468-2958.1988.tb00184.x 
Rice, R. E., Chapin, J., Pressman, R., Park, S., \& Funkhouser, E. (1996). What's in a name? Bibliometric analysis of 40 years of the Journal of Broadcasting (\& Electronic Media). Journal of Broadcasting \& Electronic Media, 40, 511-539. doi: $10.1080 / 08838159609364373$

Rogers, E. M. (1994). History of communication study. New York: Free Press.

Rogers, E. M. (1999). Anatomy of the two subdisciplines of communication study. Human Communication Research, 25, 618-631. doi:10.1111/j.1468-2958.1999.tb00465.x

Rogers, E. M., \& Chaffee, S. H. (1983). Communication as an academic discipline: A dialogue. Journal of Communication, 33, 18-30. doi:10.1111/j.1460-2466.1983.tb02402.x

Schramm, W.L. (1997). The beginnings of communication study in America: A personal memoir (S. H. Chaffee \& E. M. Rogers, Eds.). Thousand Oaks, CA: Sage.

Sherry, J. L. (2004). Media effects theory and the nature/nurture debate: A historical overview and directions for future research. Media Psychology, 6, 83-109. doi:10.1207/s1532785xmep0601_4

Song, H., Eberl, J.-M., \& Eisele, O. (2020). Less fragmented than we thought? Toward clarification of a subdisciplinary linkage in communication science, 2010-2019. Journal of Communication, 70, 310-334. doi:10.1093/joc/jqaa009

Splichal, S., \& Mance, B. (2018). Paradigm(s) lost? Islands of critical media research in communication journals. Journal of Communication, 68, 399-414. doi:10.1093/joc/jqx018

Stephen, T. (1999). Computer-assisted concept analysis of HCR's first 25 years. Human Communication Research, 25, 498-513. doi:10.1111/j.1468-2958.1999.tb00458.x 
Swanson, D. L. (1993). Fragmentation, the field, and the future. Journal of Communication, 43, 163-173. doi:10.1111/j.1460-2466.1993.tb01317.x

Thomas, G. L. (1968). Graduate degree practices in speech. The Speech Teacher, 17, 319-328. doi:10.1080/03634526809377701

Walter, N., Cody, M. J., \& Ball-Rokeach, S. J. (2018). The ebb and flow of communication research: Seven decades of publication trends and research priorities. Journal of Communication, 68, 424-440. doi:10.1093/joc/jqx015

Wartella, E. (1996). The history reconsidered. In E. E. Dennis \& E. Wartella (Eds.), American communication research: The remembered history (pp. 169-180). Mahwah, NJ: Erlbaum

Weaver, C. H. (1977). A history of the International Communication Association. Annals of the International Communication Association, 1, 607-618.

doi: $10.1080 / 23808985.1977 .11923710$

Wickham, H. (2016). ggplot2: Elegant graphics for data analysis. New York, NY: SpringerVerlag.

Wiemann, J. M., Pingree, S., \& Hawkins, R. P. (1988). Fragmentation in the field—and the movement toward integration in communication science. Human Communication Research, 15, 304-310. doi:10.1111/j.1468-2958.1988.tb00186.x

Woolbert, C. H. (1923). The teaching of speech as an academic discipline. Quarterly Journal of Speech, 9, 1-18. doi:10. 